\title{
El secreto en Calderón. Análisis de algunos aspectos del secreto en las comedias de Calderón
}

\section{Secrets in Calderón. Analyses of Some Secrecy Aspects in Calderón's Comedies}

\section{Simon Kroll}

Universität Wien

AUSTRIA

simon.kroll@googlemail.com

[Hipogrifo, (issn: 2328-1308), 3.1, 2015, pp. 19-34]

Recibido: 12-12-2014 / Aceptado: 12-01-2015

DOI: http://dx.doi.org/10.13035/H.2015.03.01.03

Resumen. El Siglo de Oro es el siglo del secreto por excelencia y de sus dramaturgos destaca Calderón como poeta de comedias de secreto. En numerosas comedias de toda su carrera alude al secreto, crea metáforas de distintos aspectos del mismo, lo aprovecha para la construcción de sus comedias de enredo; en una palabra, tiene una preocupación constante por este fenómeno antropológico que es el secreto. Se analiza el tema del secreto en algunas comedias ejemplares, tanto cómicas como serias, empezando por la figura del San Secreto presente en varias obras, entre ellas en La vida es sueño, pasando por el aspecto temporal del secreto, para terminar el artículo con algunas reflexiones acerca de la relación entre lo público y lo secreto, relación que analiza Calderón en su obra maestra al respecto: El secreto a voces.

Palabras clave. Calderón, secreto, San Secreto, público, metáforas.

Abstract. Spanish Golden Age Culture is an age of secrets and secrecy. Among its playwrights, Pedro Calderón de la Barca shows the most complex comprehension of this subject. During the entirety of his career he refers to it in numerous comedies, creates metaphors concerning different aspects of secrecy and employs it for the construction of his comedias de enredo/comedies of intrigue. In summary:

1. El presente trabajo forma parte del proyecto de investigación Secrets and Secrecy in Calderón's Comedies and in Spanish Golden Age Culture financiado por el Austrian Science Fund FWF (project number P24903-G23) y el Anniversary Fund del Oesterreichische Nationalbank (project number 14725). Le agradezco su amable ayuda a Paula Casariego, Andrea Toman-Kroll y a Camille Savage-Kroll durante la preparación de este artículo. 
Calderón has an ongoing interest in this anthropological phenomenon. The article analyses the motive of secrecy in selected plays, tragic and comic, starting with the San Secreto figure present in different plays, for example in La vida es sueño. After tracing the temporal aspect of secrecy the article ends with some thoughts about the relation between the public and the secret spheres. Calderón reflects this relation in his masterpiece concerning secrecy: El secreto a voces/The loud secret.

Keywords. Calderón, Secret, Secrecy, Metaphors, Public.

\section{UN SIGLO DE SECRETOS}

El siglo XVII es el siglo del secreto por excelencia. Abundan los manuales para secretarios, abundan los tratados de cifras, los dichos y refranes relacionados con el secreto. Con toda prudencia que supone el uso de servicios como el Ngram Viewer de Google Books, creo que nos podemos atrever a tomar esta estadística y ver cómo el uso de la palabra «secreto» llega a su cumbre en los siglos XVII y XVIII.

Ilustración 1: Ngram Viewer el empleo de «secreto» entre 1500-2000 en el ámbito hispánico

\section{Google books Ngram Viewer}

Graph these comma-separated phrases: secreto
between 1500 and 2000 from the corpus Spanish case-insensitive

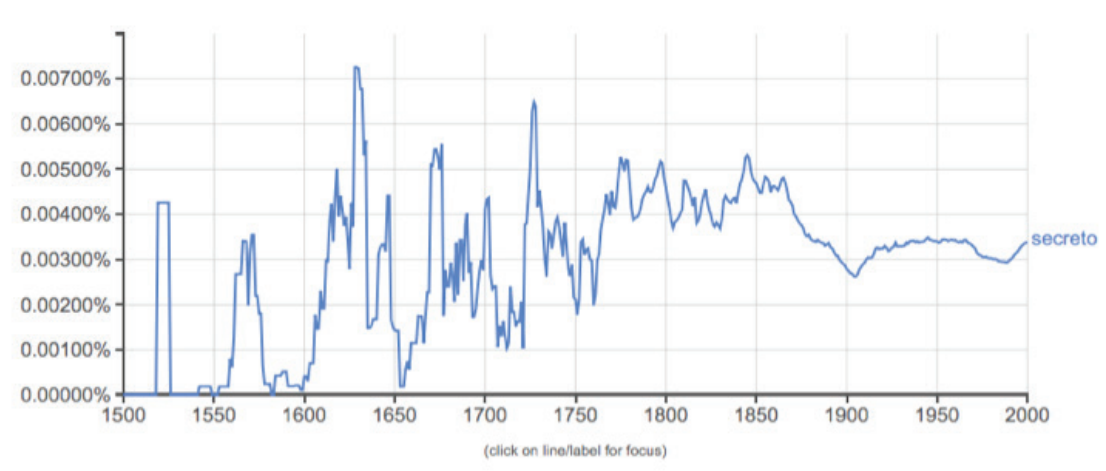

Search in Google Books:

$\begin{array}{llllll}1500-1623 & 1624-1838 & 1839-1869 & 1870-1957 & 1958-2000 & \text { secreto }\end{array}$

Hay que ser muy prudente a la hora de servirse de servicios electrónicos como el Ngram Viewer, puesto que al menos en el momento en el que se están escribiendo estas líneas no es posible adquirir informaciones detalladas sobre la composición del corpus que analiza.

Algunas precisiones ofrece el Nuevo diccionario histórico del español, que en parte contradicen los resultados del Ngram Viewer, pero no desmienten la tenden- 
cia de identificar el siglo XVII como un siglo de secretos. Según el NDHE, los Siglos de Oro de España (el XVI y XVII) son el segundo periodo que más emplea esta palabra con una frecuencia normalizada de 165.71, solo superado por el periodo de 1901-2005 con una frecuencia normalizada de 166.53².

Podemos entender estas estadísticas como un indicio más de la preocupación existente en el barroco por la declinación de lo público, de lo privado y de lo secreto. El Siglo de Oro es el siglo del secreto por excelencia y Pedro Calderón de la Barca el autor más obsesionado por este tema. El interés de Calderón por las diferentes facetas del tema del secreto es lo que se tratará de demostrar en este artículo. Tras una breve introducción al tema proporcionada por refranes auriseculares, trataré de demostrar por qué Calderón es especial en su tratamiento del secreto. Tomaré como ejemplo la metáfora del San Secreto muy frecuente en Calderón para analizar luego su aprovechamiento de los aspectos sociales y temporales del secreto. Se finalizará este artículo con una reflexión sobre la relación entre lo público y lo privado. Como se verá, Calderón comprendía con gran intuición qué fuerzas están en juego cuando estos están debatiendo sus límites.

\section{EL SECRETO: REFRANES DE UN CONCEPTO}

Dejemos atrás las perspectivas panorámicas y prestemos atención a la sabiduría popular del XVII, recogida por Correas en refranes como «Amores, diablos y dineros no pueden estar secretos», «Secreto de dos, sábelo Dios, secreto de tres, toda res»; «El secreto de tu amigo guardarás, y el tuyo no le dirás»³. Demuestran cómo se preocupaban en el barroco por la frágil frontera entre lo público y lo secreto, y el juego con el número de consabidores es más que un guiño a la pérdida de control en cuanto tres estén al tanto. Conviene preguntarse, ¿lo que saben tres ya es público? ¿Cuántos consabidores son necesarios para que algo se declare público? ¿Es acaso importante el número de confidentes? ¿Es imaginable que una información que todos conozcan permanezca secreta? Al final de este artículo volveremos sobre este aspecto.

El mundo culto de los tratadistas demuestra una ocupación no menos pequeña por este tema. Así, podemos leer en los manuales frases como «No hay duda que el secreto del príncipe honra a sus súbditos»; recogido del tratado de cifras Cifra, contracifra. Antigua y moderna de Tomás Tamayo de Vargas quien, a su vez, lo toma de una epístola de Casiodoro ${ }^{4}$. Wolfram Aichinger opina al respecto: «Los

2. Instituto de Investigación Rafael Lapesa de la Real Academia Española (2013): Corpus del Nuevo diccionario histórico (CDH) [en línea], <http://web.frl.es/CNDHE> [15/10/2014]. Según el manual de consulta, la frecuencia normalizada es el número de ocurrencias por cada millón de palabras del corpus (p. 24, n. 9).

3. Correas, 2000, p. 229; Mal Lara, 1996, p. 279 (II, 79). Muy útil herramienta al respecto es el refranero multilingüe del Centro virtual Cervantes disponible en la red, <http://cvc.cervantes.es/lengua/refranero/> [20/10/2014].

4. Tamayo de Vargas, Cifra, contracifra. Antigua y moderna, fol. 36r. Kroll, 2011, p. 292. Otro intelectual español con un conocimiento profundo del tema sería Cosme Gómez Tejada. En su libro El filósofo. Ocupaciones de nobles y discretos contra la cortesana ociosidad escribe: «El secreto del príncipe le 
poderosos del barroco dominaban el arte de conjugar lo visible con lo invisible, lo público con lo secreto, de tal modo que lo primero se alimente de la magia oscura de lo segundo» 5 .

El barroco vive, además, en los trabajos del francés Blaise Vigenère una mejora de los métodos criptológicos que volvían imposible hasta el siglo XIX el desciframiento de un mensaje sin conocer la clave. Es decir, para descifrar un mensaje que había sido encriptado con el método del criptólogo francés había que interceptar el mensajero que llevaba la clave correspondiente al texto cifrado 6 .

A nosotros, que nos llamamos modernos, nos parece fácil -quizá por el legado del barroco- comprender qué es el secreto; sin embargo, me gustaría presentar un acercamiento a este término. Esta aproximación quizá resulte incompleta dada la complejidad del tema, pero operativa para lo que me propongo en este artículo. Sigo en este esbozo a Benjamin, Simmel, algunos trabajos del matrimonio Assmann y los trabajos anteriores que Wolfram Aichinger, Alicia Vara y mi humilde persona realizaron en el marco del proyecto Secrets and Secrecy in Calderón's Comedies and Golden Age Culture?.

El secreto no es simplemente una cosa escondida, el secreto es una información cargada por unas reglas muy específicas de comunicación. Estas excluyen a unos e incluyen a otros, cerrando el paso a algunos y abriéndolo para otros. El secreto crea cercanía o distancia y produce así fronteras entre grupos sociales. Cruzarlas puede ser muy significativo para bien o para mal. De todas formas, el secreto carga una información de una energía social desbordante que pone en marcha todo un mecanismo de deseo de revelación y encubrimiento. En palabras de Simmel:

El secreto en las sociedades es un hecho sociológico primario, un género y colorido particular de la convivencia, una cualidad formal de referencia, que, en acción recíproca inmediata o mediata con otras, determina el aspecto del grupo o del elemento del grupo ${ }^{8}$.

Dada esta maquinaria y la presencia del secreto en la cultura del barroco, no es sorprendente, pues, que los poetas del siglo XVII se sirvan de esta energía social del secreto para su teatro.

hace más semejante a dios, y, por consiguiente, le granjea majestad y reverencia, suspende los vasallos, turba los enemigos» (p. 141). Muy interesante al respecto son también las reflexiones de Benavente y Benavides (1643). Ver también Pérez del Barrio Angulo (1613).

5. Aichinger, 2013, p.18.

6. Beutelspacher, 2002, pp. 23-28; Kroll, 2011, pp. 290-292.

7. Benjamin, 1991; Simmel, 1908; Assmann y Assmann, 1997; Aichinger, 2010, 2011a, 2011b, 2011c, 2011 d, 2013, 2014, Aichinger y Kroll, 2011, 2013, 2015 (en prensa); Vara, 2014; Kroll, 2011, 2014a, 2014b, 2015 (en prensa). La Revista de Occidente reúne algunos artículos muy interesantes acerca del tema en su número doble, 374-375, julio-agosto 2012.

8. Simmel, 2012, p. 82 


\section{CALDERÓN: UN AUTOR DEL SECRETO}

Muchos poetas del Siglo de Oro escribieron obras en las que el secreto o sus herramientas y técnicas adquieren un papel de protagonista. Pocos le prestaron tanta atención como don Pedro Calderón de la Barca.

Entre sus antecesores destacan comedias de secreto como El secretario de sí mismo (Lope), El secreto en la mujer (Andrés de Claramonte), Amar por señas y Amar por arte mayor (ambas de Tirso de Molina), entre otras ${ }^{9}$. Sin embargo, me parece que ninguno de los autores del Siglo de Oro tiene una preocupación tan excesiva, casi obsesiva, por el secreto como Calderón. Esta obsesión que destella en numerosas obras suyas a lo largo de toda su carrera revela una comprensión agudísima de su maquinaria y sus afectos. Su comprensión de este fenómeno es, además, otra de las muchas razones por las que Calderón no solo es también un autor moderno, sino un autor fuera del tiempo.

\section{EL SECRETO: UN ASUNTO DE SANTOS}

Pero Calderón también fue un hombre de su época y, por ello, no sorprende que se hable de santos incluso en sus comedias cómicas. Hay uno que es menos convencional y es bastante conocido porque aparece, entre otras obras, en La vida es sueño: El San Secreto. Escuchemos algunos versos famosos de Clarín al comienzo de la tercera jornada:

$$
\begin{aligned}
& \text { Si llaman santo al secreto, } \\
& \text { y santo que es de guardar, } \\
& \text { como en calendario nuevo, } \\
& \text { San Secreto es para mí. } \\
& \text { Cuando guardarle profeso, } \\
& \text { se hace día de trabajo, } \\
& \text { pues le ayuno y no le huelgo. } \\
& \text { Aunque está bien merecido } \\
& \text { el castigo que padezco, } \\
& \text { pues callé siendo } \text { criado, }^{10} \\
& \text { que es el mayor } \text { sacrilegio }^{10} \text {. }
\end{aligned}
$$

Para explicar estos versos se suele citar en muchas ediciones de La vida es sueño las siguientes palabras de Cilveti: «Clarín cree hallarse en la cárcel por no haber divulgado el secreto de Rosaura y Clotaldo, por lo que guarda el ayuno de San Secreto sin celebrar su fiesta» ${ }^{11}$. Fausta Antonucci escribe al respecto que Clarín lo llamaría San Secreto «tanto porque así alude al secreto cuyo conocimiento lo ha

9. Muy interesante parece también la obra El secretario confuso, de Jacinto Cordero, que carece de edición moderna, pero se puede leer en su Parte segunda de 1634. La figura del secretario como objeto de amores de una duquesa ha despertado cierto interés en los estudios lopescos. Algunos de los trabajos destacables son Hernández Valcárcel, 1990 y Del Río Parra, 2002.

10. Calderón, La vida es sueño, vv. 2147-2157.

11. Cilveti, citado por Rull, 1988, p. 225. 
llevado a la cárcel, como porque de hecho este santo para él es secreto, pues, aunque ayuna en su honor, no se le reconoce el derecho paralelo de holgar» ${ }^{12}$.

Clarín, efectivamente, está en la cárcel por conocer secretos, como Clotaldo declara pocos versos antes: «porque ha de estar / guardado en prisión tan grave / Clarín que secretos sabe, / porque no pueda cantar» ${ }^{13}$. Es decir, el gracioso ha entrado en terrenos del saber secreto a los que no debería tener acceso, ha cruzado una frontera significativa del conocimiento.

Pero me gustaría detenerme un poco más en la figura del San Secreto. Este parece cobrar vida a partir del refrán: «Al buen callar llaman santo (o Sancho)» ${ }^{14}$ y resulta muy barroco inventarse un santo. Es llamativo el hecho de que, por lo menos según el TESO, Calderón es el único autor del Siglo de Oro en utilizar la metáfora del San Secreto. Y no solo aparece en La vida es sueño, sino que Calderón la usa en El astrólogo fingido, El hombre pobre todo es trazas, Nadie fíe su secreto, No hay burlas con el amor y La banda y la flor ${ }^{15}$. Dado que el juego de palabras es siempre bastante parecido, nos basta ahora con la cita de La vida es sueño.

En la superficie del texto, Calderón elabora un juego de palabras entre guardar secreto y guardar el ayuno de un santo. ¿Por qué y cómo funciona la metáfora del San Secreto? Lo fundamental que tienen en común un santo y el secreto es la frontera entre el saber y no-saber. El secreto, cuando es profano, tiene una frontera relativa ${ }^{16}$; es decir, hay algo que no sé, pero si me descubren el secreto puedo llegar a saberlo, me ponen al corriente. El santo, como ser transcendente, tiene una frontera absoluta ${ }^{17}$ del conocimiento, es un secreto que no podremos revelar en esta tierra. Calderón mezcla aquí los secretos transcendentes, los secretos de la Naturaleza y de los Dioses con los secretos profanos, de la política o secretos personales ${ }^{18}$.

Ambos secretos, los absolutos y los relativos, generan su fascinación por esta frontera del conocimiento: sabemos que hay algo que no sabemos y queremos saberlo. Aparte del chiste gastado en el juego de palabras, esta figura del San Secreto revela hasta qué punto comprendía Calderón esta energía generada por esta frontera y las reglas comunicativas construidas para hablar o no hablar, para guardar o no guardar secreto. El secreto es por tanto también un asunto social de gran envergadura y complejidad.

12. Antonucci, 2008, p. 204.

13. Calderón, La vida es sueño, vv. 1998b-2001.

14. Correas, 2000, p. 54.

15. Para estos datos me baso en la base de datos digital Teatro español del Siglo de Oro (TESO). Paula Casariego ofrece un repaso por las distintas situaciones dramáticas en las que aparece en un artículo reciente dedicado al gracioso Lázaro de Nadie fíe su secreto: Casariego, 2014.

16. Término prestado de Assmann y Assmann,1997, p. 9.

17. Otro término prestado de Assmann y Assmann, 1997, p. 11

18. Ver también Assmann y Assmann, 1997, p. 10. 


\section{EL SECRETO: UN ASUNTO TEMPORAL Y SOCIAL}

El secreto como asunto social genera los típicos prejuicios hacia distintos grupos de la sociedad. Los prejuicios del Siglo de Oro opinaban que mujeres y criados no pueden guardar secreto. Calderón es más complejo, incluso cuando se mueve dentro del tópico. Aunque este cree que mujeres no pueden guardar secreto, conviene decir que en el teatro de Calderón también hay hombres que pierden el control sobre las informaciones confidenciales que tendrían que guardar.

En el ámbito de la comedia palatina, don Arias de Nadie fíe su secreto quizá sea el ejemplo más llamativo. Cargado de dos secretos, pues su amigo César y el duque Alejandro le confiesan sus amores por la misma dama, se ve obligado a ser infiel con su amigo y revelar los secretos de este ante el duque.

Diferente es la situación de Tolomeo en El mayor monstruo del mundo en cuanto a la gravedad del asunto. Le encargan asesinar a su reina Mariene, pero es incapaz de guardar el papel en que le llega la orden (compárese vv. 1929-2010 y vv. 27052726). Este acaba en las manos de Mariene que, a pesar de que este esté en pedazos, consigue descifrarlo. Cuando Tolomeo se ve confrontado con su mala gestión del asunto, suelta el tópico misógino de la mujer parlera («iQué poco duró, ay de mí, / el secreto en la mujer!», vv. 2711-2712) que resulta bastante irónico puesto que él y Mariene no acordaron ningún secreto y es él el responsable del poco tiempo que duró el encargo secreto. La diferencia entre los hombres y las mujeres incapaces de guardar un secreto radica quizá en el hecho de que para el público del Siglo de Oro resultaba risible el tópico de la mujer chismosa, mientras que los hombres podían divulgar un secreto sin convertirse en objeto de burla.

Veamos ahora cómo reaccionan los criados calderonianos ante el aspecto temporal del secreto. Fabio, criado infiel de El secreto a voces, no sabe guardar secreto, revela inmediatamente todos los secretos que se le confían. Al enterarse de algunas nuevas importantes, se explica con las siguientes palabras:

FABIO $\quad$ Hoy que tengo más que hablar,
¿ocasión he de tener
de hablar menos? Eso no,
que será piedad cruel
dejar pudrir un secreto
que a nadie sirva después,
que, corrompida la «o» en «a»,
como dijo el cordobés,
de secreto hecha secreta,
güela mal y no haga bien ${ }^{19}$.

Fabio opina que un secreto que se guarda, se pudrirá y, cambiando la «0» final en una «a», se convertirá en una secreta, es decir, una letrina, que olerá mal y no hará ningún bien. La metáfora poderosa del secreto podrido ilustra otro aspecto crucial del secreto: su dimensión temporal. Me atrevo a decir que cada secreto

19. Calderón, El secreto a voces, vv. 2832-2841. 
tiene su fecha de caducidad. Cifrar un mensaje no es otra cosa que postergar el momento en el que el adversario se entere del contenido de la carta. «Nadie mejor que el muerto / guarda un secreto ${ }^{20}$ dice Leonido en Hado y divisa de Leonido y Marfisa, pues el muerto queda ya fuera del marco temporal. Hay un momento en que la revelación de un secreto ya caducado no tiene mayores consecuencias. Niklas Luhmann diferencia tres aspectos del secreto: el social, el de su contenido y el aspecto temporal ${ }^{21}$. No da igual con qué personas se comparte un secreto o a qué personas se excluye del círculo de los privilegiados consabidores. De la misma manera es importante el momento en el que se decide descubrir un secreto: las relaciones familiares pueden cambiar radicalmente después de la apertura de un testamento, por ejemplo.

Fabio lleva al extremo esta última característica del secreto y revela todo con la mayor rapidez posible: antes de que se pudra. Apunta Wolfram Aichinger:

En las comedias nos encontramos a tantísimos graciosos que se entretienen penetrando, vendiendo o, en algunos casos, también guardando secretos. Hacen de espías y agentes dobles en el ámbito peligroso del palacio en donde no existe límite claro entre lo privado y lo político ${ }^{22}$.

Calderón comprende tanto el gusto de guardar secreto como el de revelarlo. Sirvan de ejemplo estas palabras de Inés de El hombre pobre todo es trazas:

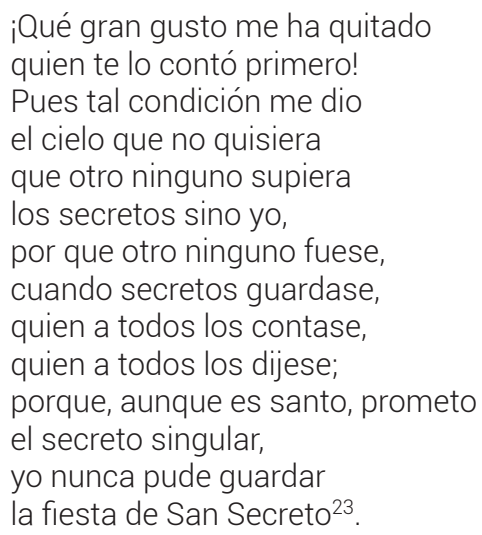

A los pocos versos se siente casi arrepentida por su revelación, que, sin embargo, justifica por el gusto que le provocó:

\section{¡Oh, nunca yo hubiera hablado! \\ Pero no será el disgusto}

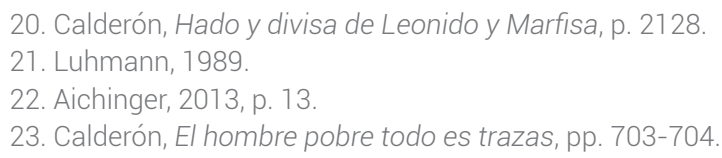


tan grande como fue el gusto

del haberlo publicado ${ }^{24}$.

Este aspecto temporal del secreto no solo se tematiza por los personajes agentes de la revelación de secretos, sino que Calderón lo utiliza para la construcción de los enredos de sus comedias. Cuando su construcción lo pida, el gusto de publicar secretos se ve emparejado por el aprovechamiento de la revelación de secretos como efecto dramático.

Beatriz, criada de María en El astrólogo fingido, es encargada del amor secreto de María. Esta dama le dice:

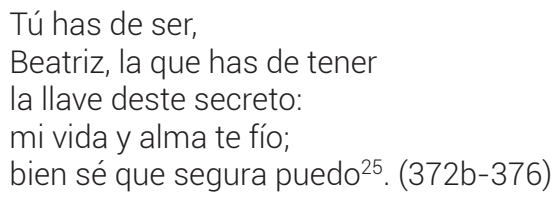

Beatriz se muestra en un primer momento fiel a su ama, pero se rinde a los 300 versos a los sobornos de don Diego, que quiere conquistar el corazón de María. El galán envía a su criado Morón para penetrar los secretos del corazón de María y, en confianza, Beatriz le pide al gracioso:

$$
\begin{aligned}
& \text { Yo, Morón, te lo dijera } \\
& \text { si me juraras aquí } \\
& \text { tenerme siempre secreto }{ }^{26} \text {. }
\end{aligned}
$$

A continuación, descubre todo el secreto y es precisamente esta revelación la que pone en marcha toda la maquinaria cómica de la comedia, que consiste en que don Juan corteja a María en secreto fingiendo no estar en Madrid, sino sirviendo a la corona como soldado en Flandes. Parte de la gracia de la obra radica en que don Juan cree seguro su secreto, mientras que todo Madrid está al tanto de que permanece en la ciudad gracias al descubrimiento del secreto por parte de Beatriz. El secreto se volvió público y solo lo ignora la persona supuestamente escondida. Este aspecto diferencia a Calderón de otros autores del Siglo de Oro. Wolfram Aichinger y yo apuntamos en un trabajo anterior: «While developing and improving models provided by others, Calderón shows the greatest mastery in his use of secrecy as a dramatic technique» ${ }^{27}$.

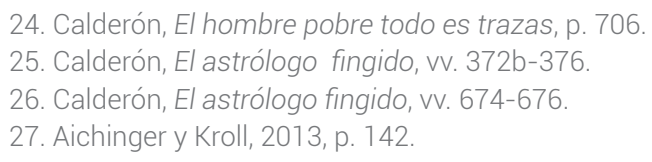




\section{EL SECRETO: UN ASUNTO PÚBLICO}

La obra maestra del secreto es, sin lugar a dudas, El secreto a voces. Reúne la presencia de alusiones explícitas a las técnicas y los afectos del secreto con un aprovechamiento magistral del secreto como efecto dramático.

Me gustaría resaltar el título de la obra: El secreto a voces. ¿Qué es un secreto a voces? Al igual que el secreto, es una información cargada de reglas comunicativas. El secreto a voces no debe ser pronunciado, pero, a diferencia del secreto, no hay personas que no estén al tanto, es decir, que todos conocen el secreto. El secreto a voces es la crisis del secreto, pues vuelve borrosas las fronteras que al secreto tanto le hubiera gustado definir claramente: allá, lo apartado, lo secreto; aquí, lo público. El secreto a voces es lo apartado dentro del terreno público.

Calderón conocía muy bien la frágil frontera entre lo público y lo secreto. Escuchemos los planes de intriga de Libio en La gran Cenobia:

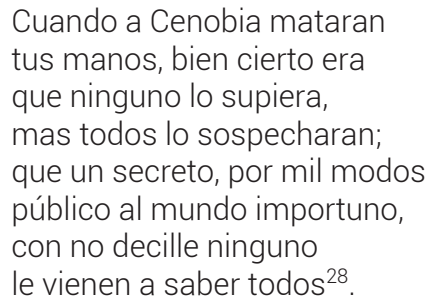

Asimismo Wolfram Aichinger escribe sobre esta frontera borrosa:

Lo secreto y lo público [...] constituyen esferas bien separadas en continua compleja interacción e interferencia. Asimismo muestran un frecuente transitar de elementos. De algún modo, todo secreto es 'secreto a voces'. Calderón lo intuye con su genio y gran intuición antropológica y sociológica ${ }^{29}$.

El secreto y lo público viven en continuo debate de sus fronteras. Volviendo a El secreto a voces, conviene decir que la obra conoce de entrada muchos secretos: hay duques disfrazados de sus propios secretarios, amores secretos en la primera dama y el primer galán, un criado sobornado e infiel a su amo, etc. ¿Y cuál es el secreto a voces? Aparte de que todos los secretos sean secretos a voces para el público, parece que hay uno que es un secreto a voces en escena: los amores indebidos de la duquesa Flérida por su secretario Federico. En ningún momento llegan a pronunciarse directamente, están en el aire en cada verso. Pero Calderón no sería Calderón si le bastara el sentido recto de un refrán. Ya Canavaggio señaló este uso complejo de refranes en el teatro de Calderón, eligiendo como ejemplo las obras El hombre pobre todo es trazas, Cada uno para sí y El agua mansa. Concluía el estudioso: 
De los tres ejemplos aquí examinados se deduce que la interrelación entre comedia y refrán, aunque sometida a las vicisitudes inherentes a cada intriga, se rige en fin de cuentas por un protocolo determinado una vez por todas. El momento de la exposición se caracteriza siempre por una proyección del refrán -discurso simple, pero generalizador- sobre la comedia a la que califica -discurso complejo, pero particularizador. En un segundo tiempo, la creciente complicación de la intriga acarrea una reversión de la fábula sobre el refrán, que supone una manera de contralectura del aserto proverbial ${ }^{30}$.

El caso de El secreto a voces no es del todo análogo, pero el refrán ${ }^{31}$ también cobra un nuevo sentido después de la exposición. En la segunda jornada, el secreto a voces (secreto público) se convierte en un secreto que se dice a voces: un secreto a voces. Los amantes secretos Laura y Federico usan un lenguaje cifrado, un acróstico, para hablar delante de todos sin ser descubiertos. «Paréceme que será / el secreto a voces ese» ${ }^{32}$ dice Laura cuando Federico le explica el método de cifrar su comunicación. En los secretos a voces (los mensajes cifrados de Federico y Laura), lo secreto se encubre en el espacio público, mientras que el secreto a voces del amor de Flérida por Federico nunca llega a pronunciarse.

Tal vez sea esta una de las funciones de la comedia, función que cumple aun cuando parece contar una historia ligera y alejada de la realidad política: escenifica y hace visible los agentes del secreto, sus medios y dispositivos: guantes, cartas, cifras, esbozos, máscaras, celosías o palabras que sirven para esconder palabras $^{33}$

\section{CONCLUSIONES}

La presencia del secreto en la obra de Calderón es Ilamativa y sería simplificador explicarla como mera convención literaria de la comedia de enredo. Especialmente las comedias cómicas se nutren de las vicisitudes del secreto; no obstante, las agudas reflexiones sobre el secreto aparecen tanto en obras cómicas como en las serias. Una lectura atenta de este fenómeno tampoco supone un nuevo intento de una lectura trágica de obras cómicas, tan criticado por Luis Iglesias Feijoo y otros especialistas ${ }^{34}$. Calderón tenía una comprensión extraordinaria del fenómeno humano que es el secreto y lo aprovecha para una construcción casi perfecta de sus comedias cómicas. Además, su entendimiento de dicho fenómeno le incita a crear metáforas fascinantes del tema, combinar el uso de cifras como efecto dramático con la matemática de sus obras, y de dispersar comentarios explícitos a los mecanismos del secreto por toda su obra. En todo ello demuestra que su comprensión del secreto va mucho más allá de unas oposiciones binarias entre lo público y lo secreto, sino que nos muestra y ejerce sobre el tablado el continuo debate entre

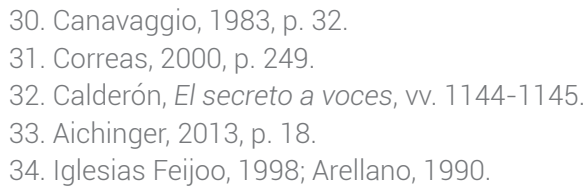


ambos espacios, dejando borrosa la frontera entre las dos esferas. Y sí, Calderón es un autor muy poco extraño, al contrario de lo que algunos afirman ${ }^{35}$, y su tratamiento del secreto es una razón más que lo convierte, en muchas ocasiones, en nuestro contemporáneo ${ }^{36}$.

\section{BIBLIOGRAFÍA}

Aichinger, Wolfram, «Lautes Verheimlichen und leises Enthüllen. Zu Calderóns El secreto a voces und den Geheimsprachen der barocken Komödie», 2010, $<$ http://theater-archiv.zesar.net/doc/geheimnisse.pdf> [18/10/2013].

Aichinger, Wolfram, «Beichtväter, Sekretäre und Agenten. Figuren und Medien der Geheimhaltung in der Politik und ihr Widerhall im Theater», en Laute Geheimnisse. Calderón und die Chiffren des Barock, ed. Wolfram Aichinger y Simon Kroll, Wien, Turin + Kant, 2011a, pp. 223-252.

Aichinger, Wolfram, "Hablar delante de todos / conmigo solo". Tiempo, espacio dramático y comunicación en El secreto a voces de Calderón de la Barca», en Especificidad del texto dramático y la puesta en escena: dependencia o autonomía. «Encuentros 2010», ed. Urszula Aszyk, Varsovia, Instituto de Estudios Ibéricos e Iberoamericanos, 2011b, vol. 2, pp. 19-27.

Aichinger, Wolfram, «Laute Geheimnisse. Verheimlichen, Chiffrieren und Enthüllen in Calderóns Komödie und der Kultur des Barock», en Laute Geheimnisse. Calderón und die Chiffren des Barock, ed. Wolfram Aichinger y Simon Kroll, Wien, Turin + Kant, 2011c, pp. 31-68.

Aichinger, Wolfram, «"Sin secreto no hay amor". Liebe am Hof und die Geheimnisse in Calderóns Leben», en Laute Geheimnisse. Calderón und die Chiffren des Barock, ed. Wolfram Aichinger y Simon Kroll, Wien, Turin + Kant, 2011d, pp. 265-283.

Aichinger, Wolfram, «Confesores, espías, secretarios. Los agentes ocultos del poder y su representación en el teatro de Calderón», en Teatro y poder en el Siglo de Oro, ed. Mariela Insúa y Felix K. E. Schmelzer, Pamplona, Servicio de Publicaciones de la Universidad de Navarra (Colección BIADIG)/Publicaciones Digitales del GRISO, 2013, pp. 9-21.

Aichinger, Wolfram, «El secreto en la comedia de Calderón y en la vida cortesana», en Pictavia aurea. Actas del IX Congreso de la Asociación Internacional «Siglo de Oro», dir. Alain Bègue y Emma Herrán Alonso, Toulouse, Presses Universitaires du Mirail (Anejos de Criticón, 19), 2014, pp. 705-712.

Aichinger, Wolfram y Simon Kroll (eds.), Laute Geheimnisse. Calderón und die Chiffren des Barock, Wien, Turin + Kant, 2011.

35. El hispanista alemán Hugo Friedrich escribió un libro sobre la supuesta alteridad de Calderón con el título: Calderón, ese extraño. Ver Friedrich, 2006

36. Tomo prestado este epíteto de un libro ya clásico para lo estudios calderonianos: Ruiz Ramón, 2000 . 
Aichinger, Wolfram y Simon Kroll, «Secrets and Secrecy in Calderón's Comedies and in Spanish Golden Age Culture. Outline of a New Research Focus in Calderonian Studies», Hipogrifo, 1, 2, 2013, pp. 135-144, <http://dx.doi.org/ 10.13035/H.2013.01.02.12>.

Aichinger, Wolfram y Simon Kroll, «"Una mona en castellano son 100 monas en guarismo". Número, geometría, desdoblamiento reflexivo y cifra en las comedias de Calderón», (en preparación).

Antonucci, Fausta, «Prólogo y notas», en Calderón de la Barca, Pedro, La vida es sueño, ed. Fausta Antonucci, Barcelona, Crítica, 2008, pp. 7-109.

Arellano, Ignacio, «El extraño Calderón o las extrañas cosas que a Calderón suceden», en Diferentes y escogidas. Homenaje al profesor Luis Iglesias Feijoo, ed. Santiago Fernández Mosquera, Madrid/Frankfurt am Main, Iberoamericana/ Vervuert, 2014, pp. 41-56.

Assmann, Aleida y Jan Assmann (eds.), Schleier und Schwelle. Geheimnis und Öffentlichkeit [Archäologie der literarischen Kommunikation V, 1], München, Fink, 2002.

Benavente y Benavides, Cristóbal de, Advertencias para reyes, príncipes y embajadores, Madrid, Francisco Martínez, 1643.

Benjamin, Walter, «Über das Rätsel und das Geheimnis», en Benjamin, Walter, Gesammelte Schriften, vol. VI, ed. Rolf Tiedemann y Hermann Schweppenhäuser, Frankfurt am Main, 1991, pp. 17-18.

Beutelspacher, Albrecht, Geheimsprachen. Geschichte und Technicken, München, Beck, 2002.

Calderón de la Barca, Pedro, El astrólogo fingido, ed. Fernando Rodríguez-Gallego, Kassel, Reichenberger, 2011.

Calderón de la Barca, Pedro, La gran Cenobia en Comedias, II. Segunda parte de comedias, ed. Santiago Fernández Mosquera, Madrid, Biblioteca Castro, 2007, pp. 307-396.

Calderón de la Barca, Pedro, Hado y divisa de Leonido y Marfisa, en Obras completas, Comedias, t. I, ed. Ángel Valbuena Briones, Madrid, Aguilar, 1987, pp. 2098-2151.

Calderón de la Barca, Pedro, El hombre pobre todo es trazas en Comedias, I. Primera parte de comedias, ed. Luis Iglesias Feijoo, Madrid, Biblioteca Castro, 2006, pp. 651-736.

Calderón de la Barca, Pedro, El mayor monstruo del mundo, ed. María J. Caamaño Rojo, Santiago de Compostela, 2006 (tesis doctoral).

Calderón de la Barca, Pedro, Nadie fíe su secreto, en Obras completas, Comedias, t. I, ed. Ángel Valbuena Briones, Madrid, Aguilar, 1987, pp. 93-125. 
Calderón de la Barca, Pedro, La primera versión de La vida es sueño, ed. José María Ruano de la Haza, Liverpool, Liverpool University Press, 1992.

Calderón de la Barca, Pedro, El secreto a voces, ed. Wolfram Aichinger y Simon Kroll, en colaboración con Fernando Rodríguez-Gallego, Kassel, Reichenberger, 2015.

Canavaggio, Jean, «Calderón entre refranero y comedia: de refrán a enredo», en Aureum Saeculum Hispanum. Beiträge zu Texten des Siglo de Oro. Festschrift für Hans Flasche zum 70. Geburtstag, ed. Karl Herman Körner y Dietrich Briesemeister, Wiesbaden, Franz Steiner Verlag, 1983, pp. 27-35.

Casariego Castiñeira, Paula, «Hacia la construcción del gracioso Lázaro: principales mecanismos de comicidad en Nadie fíe su secreto», Cuadernos de Aleph, 6, pp. 58-79.

Claramonte, Andrés, El secreto en la mujer, ed. Alfredo Rodríguez López-Vázquez, London, Tamesis, 1991.

Cordero, Jacinto, El secretario confuso en Segunda parte de las comedias del Alférez Jacinto Cordero, Lisboa, Craesbeeck, 1634, fols. 1r-21v.

Correas, Gonzalo, Vocabulario de refranes y frases proverbiales (1627), ed. Louis Combet, Madrid, Castalia, 2000.

Friedrich, Hugo, Calderón, ese extraño, Pontevedra, Mirabel, 2006.

Gómez Tejada, Cosma, El filósofo. Ocupaciones de nobles y discretos contra la cortesana ociosidad, Madrid, Domingo García y Morrás, 1650.

Hernández Valcárcel, Carmen, «El tema de la dama enamorada de su secretario en el teatro de Lope de Vega», en Estado actual de los estudios sobre el Siglo de Oro. Actas del II Congreso Internacional de Hispanistas del Siglo de Oro, vol. I, ed. Manuel García Martín, Ignacio Arellano, Javier Blasco y Marc Vitse, Salamanca, Ediciones Universidad de Salamanca, 1990, pp. 481-495.

Iglesias Feijoo, Luis, «"Que hay mujeres tramoyeras": la matemática perfecta de la comedia calderoniana», en La comedia de enredo, ed. Felipe B. Pedraza Jiménez y Rafael González Cañal, Almagro, Universidad de Castilla-La Mancha/ Festival de Almagro, 1998, pp. 201-236.

Instituto de Investigación Rafael Lapesa de la Real Academia Española (2013): Corpus del Nuevo diccionario histórico (CDH) [en línea], <http://web.frl.es/CNDHE> [15/10/2014].

Kroll, Simon, «Chiffren und ihre Sekretäre. Ein unveröffentlichtes Manuskript von Tomás Tamayo de Vargas aus dem 17. Jahrhundert», en Laute Geheimnisse. Calderón und die Chiffren des Barock, ed. Wolfram Aichinger y Simon Kroll, Wien, Turin + Kant, 2011a, pp. 285-304.

Kroll, Simon, «Die Monas und der Glaser von Tetuán. Zifferncode, arabische Mathematik und das Chaos des Entschlüsselns», en Laute Geheimnisse. Calderón 
und die Chiffren des Barock, ed. Wolfram Aichinger y Simon Kroll, Wien, Turin + Kant, 2011b, pp. 69-84.

Kroll, Simon, «Jardines en las comedias de Calderón», en Especificidad del texto dramático y la puesta en escena: dependencia o autonomía. «Encuentros 2010», coord. Urszula Aszyk, Varsovia, Instituto de Estudios Ibéricos e Iberoamericanos, 2011c, vol. II, pp. 29-38.

Kroll, Simon, «Cifras y sus secretarios. Un manuscrito desconocido de Tomás Tamayo de Vargas», Estudios Hispánicos, XX, 2012, pp. 59-66.

Kroll, Simon, «Perspectivas múltiples en el lenguaje de los cuentos de Calderón. Burlas -consejos - filosofía. Las monas y el vidriero de Tetuán», en Pictavia aurea. Actas del IX Congreso de la AISO 2017 (Poitiers, 11-15 de julio de 2017), ed. Alain Bègue y Emma Herrán Alonso, Toulouse, Presses Universitaires du Mirail (Anejos de Criticón, 19), 2013, pp. 929-936.

Lochrie, Karma, Covert Operations. The Medieval Uses of Secrecy, Philadelphia, University of Pennsylvania Press, 1999.

Mal Lara, Juan de, Philosophia vulgar, ed. Manuel Bernal Rodríguez, Madrid, Biblioteca Castro, 1996.

Pérez del Barrio Angulo, Gabriel, Dirección de secretarios de señores, y las materias, cuidados, y obligaciones que les tocan: con las virtudes de que se han de preciar, estilo y orden del despacho y expediente, manejo de papeles de ministros, formularios de cartas, provisiones de oficios, y un compendio en razón de acrecentar estado, y hacienda, oficio de contador, y otras curiosidades, Madrid, Alonso Martín de Balboa, 1613.

Revista de Occidente, El secreto, 374-375, julio-agosto 2012.

Río Parra, Elena del, «La figura del secretario en la obra dramática de Lope de Vega», Hispania, 85.1, 2002, pp. 12-21.

Ruiz Ramón, Francisco, Calderón nuestro contemporáneo, Madrid, Castalia, 2000.

Rull Fernández, Enrique, «Estudio y notas» en Calderón de la Barca, Pedro, La vida es sueño, ed. Enrique Rull Fernández, Madrid, Alhambra, 1988, pp. 3-102.

Sevilla, Julia y María I. Teresa Zurdo Ruiz-Ayúcar, Refranero multilingüe del Centro virtual cervantes, <http://cvc.cervantes.es/lengua/refranero/> [20/10/2014].

Simmel, Georg, "Das Geheimnis und die geheime Gesellschaft», en Soziologie. Untersuchungen über die Formen der Vergesellschaftung, Berlin, Duncker \& Humblot Verlag, 1908, pp. 256-304.

Simmel, Georg, «La sociedad secreta», Revista de Occidente, 376 (número especial sobre El secreto), 2012, pp. 82-95 [fragmentos de «El secreto y la sociedad secreta», de su libro Sociología. Estudios sobre la forma de socialización].

Tamayo de Vargas, Tomás, Cifra, contracifra. Antigua y moderna, ms. 1612 [BNE, MSS/8940]. 
Taussig, Michael, Defacement. Public Secrecy and the Labor of the Negative, Stanford, Stanford University Press, 1999.

Tirso de Molina (Fray Gabriel Téllez), Amar por señas, en Obras dramáticas completas, t. I, ed. Blanca de los Ríos, Madrid, Aguilar, 1946, pp. 1769-1815.

Tirso de Molina (Fray Gabriel Téllez), Amar por arte mayor, en Obras dramáticas completas, t. III, ed. Blanca de los Ríos, Madrid, Aguilar, 1958, pp. 1167-1210.

Vara López, Alicia, «El fuego en cárceles de nieve: del secreto amoroso en la comedia calderoniana», Hipogrifo, 2.1, 2014, pp. 73-85 <http://dx.doi.org/ 10.13035/H.2014.02.01.05>.

Vega, Lope de, El secretario de sí mismo, en Obras completas. Comedias XIV, ed. Jesús Gómez y Paloma Cuenca, Madrid, Biblioteca Castro, 1998, pp. 1-100. 